\title{
Residual Stress Characterization and Control in the Additive Manufacture of Large Scale Metal Structures
}

\author{
Jan Roman Hönnige ${ }^{1, a^{*}}$, Stewart Williams ${ }^{1, b}$, Matthew J. Roy ${ }^{2, c}$, \\ Paul Colegrove ${ }^{1, d}$, Supriyo Ganguly ${ }^{1, e}$ \\ ${ }^{1}$ Welding Engineering and Laser Processing Centre, Cranfield University, MK43 OAL Cranfield, \\ UK \\ ${ }^{2}$ School of Mechanical, Aerospace and Civil Engineering, University of Manchester, M14 9PL \\ Manchester, UK \\ aj.honnige@cranfield.ac.uk, s.williams@cranfield.ac.uk, ' $m$ matthew.roy@manchester.ac.uk, \\ dp.colegrove@cranfield.ac.uk, ês.ganguly@cranfield.ac.uk
}

Keywords: Additive Manufacturing; Neutron Diffraction; Contour Method; Cold Rolling; Pinch Rolling

\begin{abstract}
Additive Manufacture of metals is an area of great interest to many industrial sectors. All metal additive manufacturing processes suffer with problems of residual stresses and subsequent distortion or performance issues. Wire + Arc Additive Manufacture (WAAM) is a metal additive manufacture process that is suitable for the production of large scale engineering structures. Paramount to the successful industrial application of WAAM is the understanding and control of residual stress development and their subsequent effects. Vertical inter-pass rolling can be used to reduce these residual stresses, but its potential is limited due to the absence of lateral restraint of the wall. So it deforms the wall in its transverse direction rather than reducing longitudinal tensile residual stresses, which is the main source of the distortion. The potential of a new pinch-roller concept is currently being investigated at Cranfield University with very promising preliminary results: It was possible to entirely eliminate the distortion of a Ti-6Al-4V WAAM wall.
\end{abstract}

\section{Introduction}

Wire + arc additive manufacturing (WAAM) is a robotic and welding equipment based highdeposition-rate additive manufacturing (AM) process, which can be used for the manufacture of large-scale aerospace parts. Fig. 1 shows a Ti-6Al-4V landing gear rib near-net-shape demonstrator part manufactured with WAAM. Compared to conventional subtractive machining, the main benefits of WAAM are the significant time, material, and cost savings.

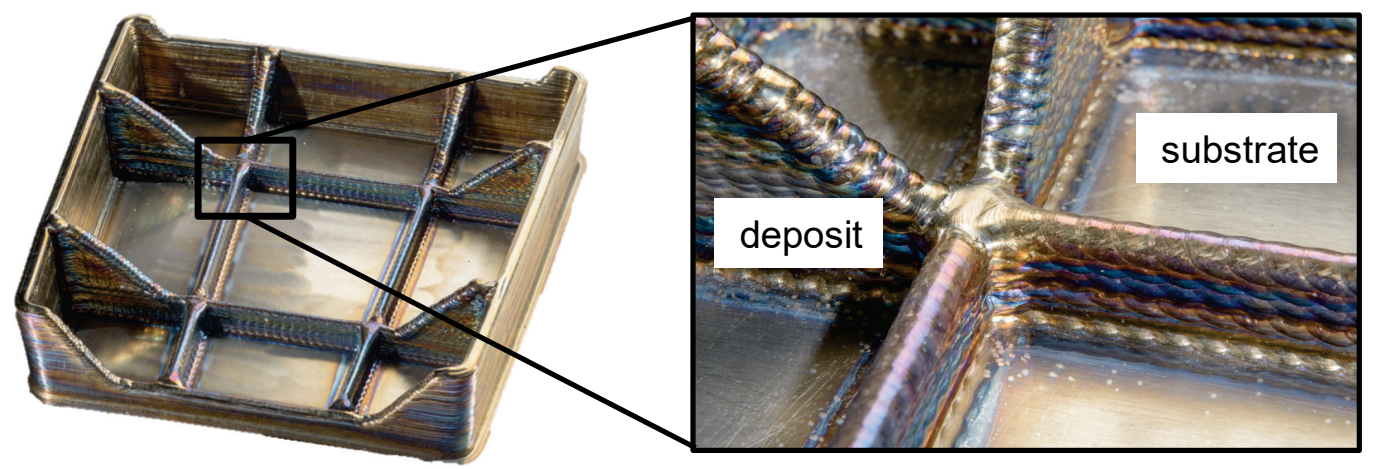

Figure 1: WAAM Demonstrator: Bombardier Landing Gear Rib; Ti-6Al-4V; $0.7 \mathrm{~m} ; 20 \mathrm{~kg}$

(c) (1) Content from this work may be used under the terms of the Creative Commons Attribution 3.0 license. Any further distribution of this work must maintain attribution to the author(s) and the title of the work, journal citation and DOI. Published under license by Materials Research Forum LLC. 
The process can be used to deposit a range of materials including stainless steel and Al-alloys. However Ti-6Al-4V is the material to benefit most from the advantages of WAAM, due to the commonly high material and process costs. Suitable equipment to deposit Ti-6Al-4V wire is TIG and Plasma heat sources. A high deposition rate is generally achieved at the expense of the minimum feature size. The genuine targets of a high-deposition rate process are material-, lead time- and cost savings of large parts with medium complexity rather than design or feature freedom [1].

The deposition of liquid metal on a solid substrate and its' constrained shrinkage during cooling causes elastic and plastic deformation. In the longitudinal direction, the tensile residual stresses appear to be highest. The temperature-dependent flow strength and thermal properties of the metal determine the magnitude of these residual stresses [2]. In steel the residual stresses can be as high as the materials yield stress at room temperature. After unclamping, the section shows a significant outof-plane distortion and the longitudinal residual stresses redistribute from being constant along the height into dropping linearly [3]. The redistribution and resulting distortion due to unclamping is illustrated in Fig. 2 a) to c).
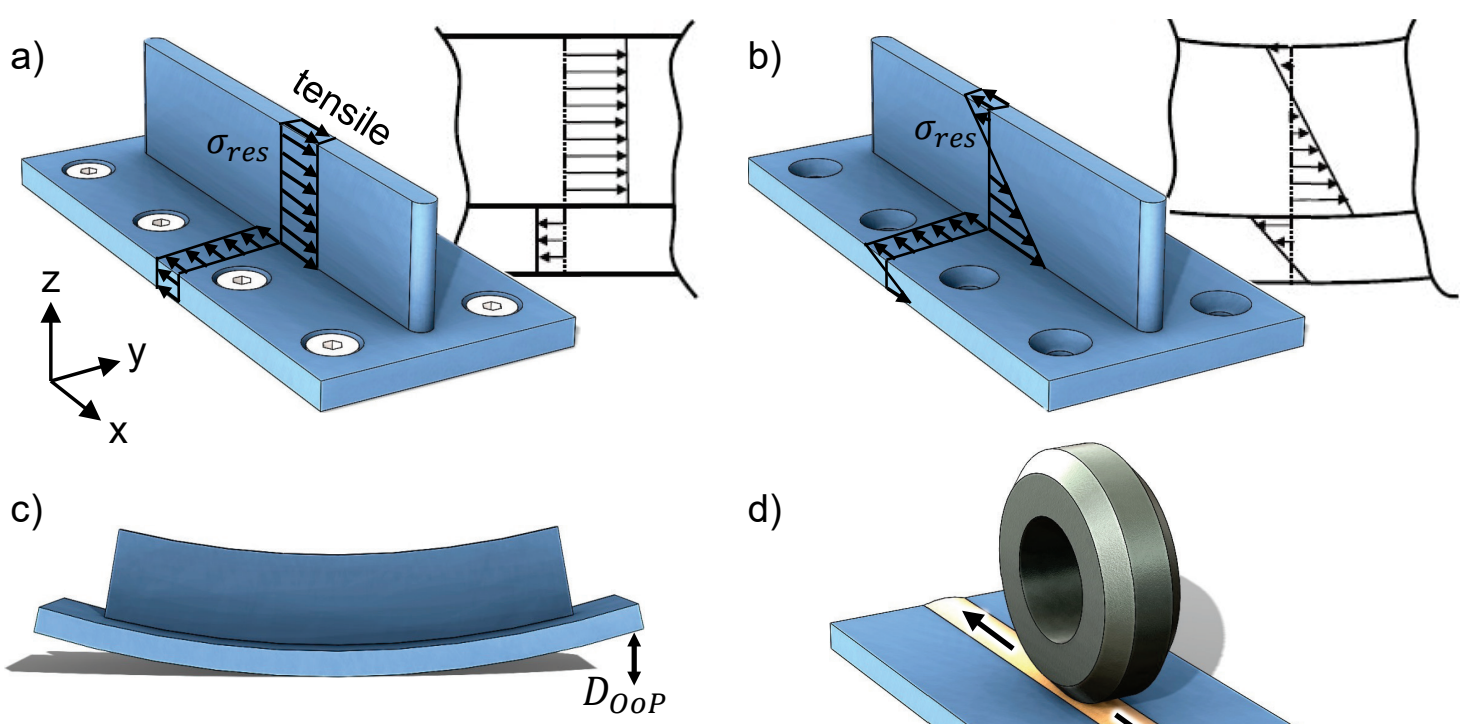

d)

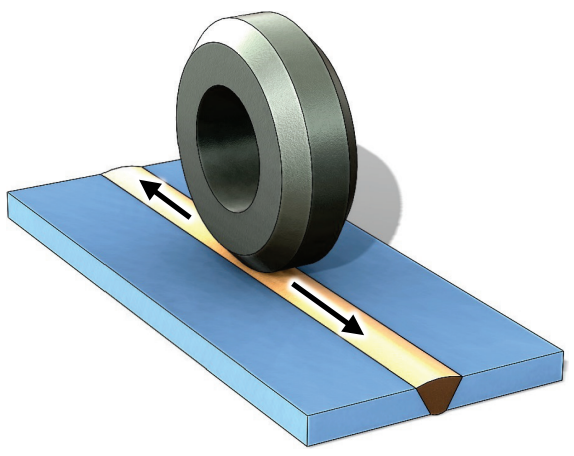

e)

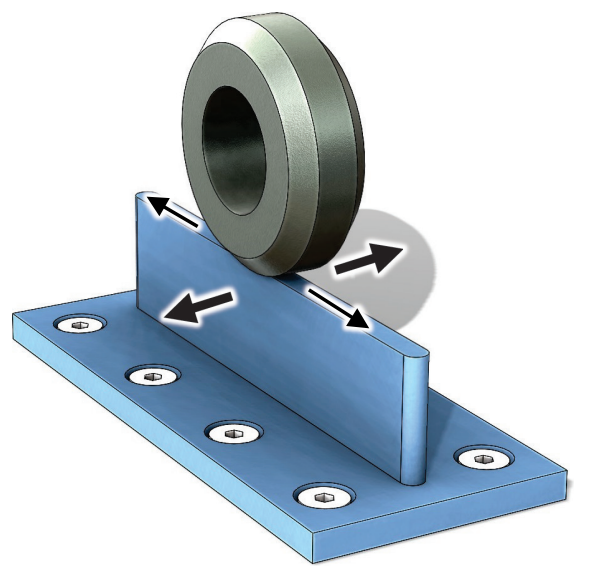

f)

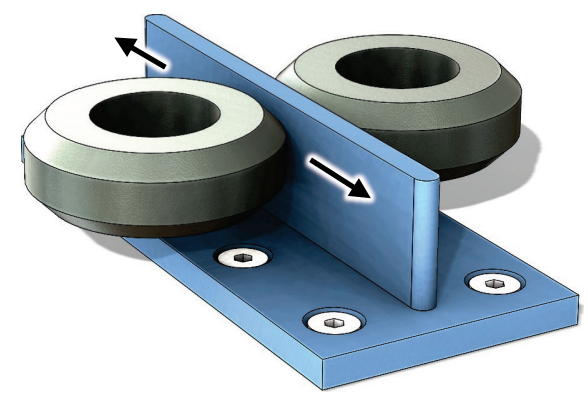

Figure 2: Residual Stress and Distortion in WAAM: Stress Field in a clamped a) and unclamped Section [3]; c) Out-of-Plane Distortion D of the un-clamped Section; d) inducing Longitudinal Strain into Butt-Welds by vertical Rolling; e) inducing predominantly undesired lateral Strain in WAAM wall by vertical Rolling; f) Concept of Pinch-Rolling

The relatively young and destructive Contour Method (CM) is the only concurrent residual stress measurement technique to provide a full 2-D stress map over the cross section with the required 
spatial resolution. The more established Neutron Diffraction (ND) technique can profile full residual stress tensors along characteristic lines with limited resolution, driven by the material. Both, CM and ND are powerful tools to investigate the development of the residual stresses in WAAM, which is vital to evaluate potential applications to control them [4].

A promising mechanical technique to manipulate the residual stresses and distortion is cold rolling, which initially has been used on butt welds (Fig. 2 d), because it can eliminate residual stresses and distortion efficiently and entirely by inducing compressive strain in the longitudinal welding direction [5]. In additive manufacturing the deformation is mainly induced in the transverse direction instead, because of the absence of lateral restraint (Fig. 2 e). Hence vertical rolling can only reduce residual stress and distortion in Ti-6Al-4V WAAM, but not eliminate them entirely [4]. In Colegrove et al. [3] this lateral deformation was successfully attempted to restrain for the first time by using "slotted roller". It shows a greater improvement on the distortion compared to other "flat" or "profiled" roller geometries. However, the use of the slotted roller is very cumbersome, time consuming and limited.

A new concept is pinch-rolling (Fig. 2 f), which would roll the wall from both sides. This would prevent the lateral deformation and keep the rolling forces in the tool instead of the entire frame. Before developing this tool, the existing vertical rolling equipment will be used to roll on one side of the wall as a preliminary study. In the present work we show the effect of side rolling a Ti-6Al-4V single-path WAAM part on the residual stress and distortion.

\section{Methodology}

Nine Ti-6Al-4V walls were built using a plasma power supply. After the final layer, the wall remained clamped on the aluminium backing bar and cooled to room temperature for cold side-rolling. The specimen was turned by $90^{\circ}$, so that one side of the deposit evenly rested on a tool steel block, as shown in Fig. 3. A hydraulic cylinder was used to roll both sides of four specimens with $100 \mathrm{kN}, 130 \mathrm{kN}, 160 \mathrm{kN}$ and $190 \mathrm{kN}$ respectively using a large roller. The same was done on four other samples with a smaller roller diameter. The ninth sample was the control sample. After unclamping, a height gauge was used to measure the out-of-plane distortion D of the unclamped sample.
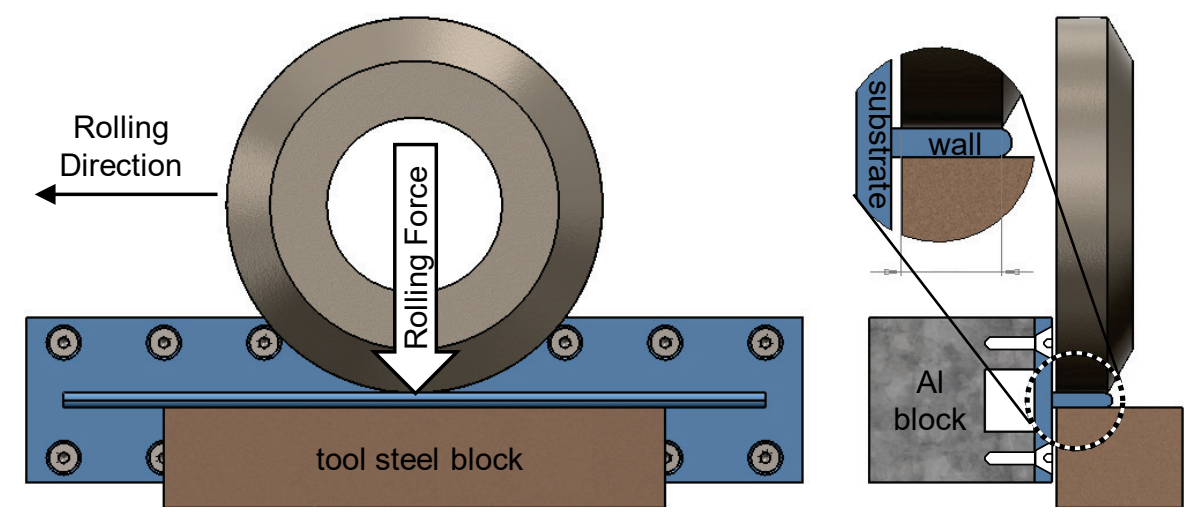

Figure 3: Schematic of Side-Rolling

Neutron Diffraction strain analysis was carried out at the ENGIN_X instrument at ISIS Rutherford Appleton Laboratory in Didcot/UK. Ten gauge volumes along the vertical centreline of $2 \times 2 \times 2 \mathrm{~mm}$ each were exposed to the monochromatic beam for $40 \mu \mathrm{A}$ counting time. The single peaks of the $\{103\}_{\alpha}$ and $\{101\}_{\alpha}$ hkl planes were fitted individually to determine their spacing. With these, residual stresses were calculated using Hooks law with the following plane specific values: $\mathrm{d}_{0,103}=1.3253 \AA$, $\mathrm{d}_{0,101}=2.2238 \AA, \quad \mathrm{E}_{103}=108.3 \mathrm{MPa}, \quad \mathrm{E}_{101}=126.96 \mathrm{MPa}, \quad v_{103}=0.285 \quad$ and $v_{101}=0.39 . \quad$ The longitudinal residual stresses calculated from both planes agreed well and were averaged.

Afterwards, the CM was employed on the same specimens at the University of Manchester to generate a stress map on the longitudinal yz-plane in the centre of the sample by cutting specimens 
via Electro-Discharge Machining (EDM) and numerically analysing the resulting relaxation. With Neutron diffraction, three profiles were generated: The first two profiles were taken from the unrolled control specimen in two different conditions. The first condition was the still-clamped condition and the second the unclamped and distorted condition. One wall that has been side rolled was also measured in the unclamped condition. With CM, the same samples were measured, aside from the clamped control. To extract the most detail from CM, an analysis route was selected with a very fine numerical description of the cross-section, approaching twice that of the wire diameter (250 $\mu \mathrm{m})$ employed for cutting. While very fine spatial resolution was obtained, this was at the expense of potentially incorporating small variations in the cut surface in the resolved stress.

\section{Results and Discussion}

Distortion. The Out-of-Plane distortion of the control sample is $6.8 \mathrm{~mm}$, which is comparable to what has been found before [4]. Fig. 4 shows the distortion of the eight rolled samples vs. the rolling load. Post-weld side rolling shows a greater reduction in distortion with increasing rolling loads and decreasing roller diameter as known from previous work [4], [6]. Comparing the roller diameters, the smaller roller always showed a greater reduction in distortion for the same load by approximately $1 \mathrm{~mm}$. For both rollers, the distortion closest to zero has been achieved using $130 \mathrm{kN}$ load. The result suggests that $\sim 85 \% \ldots 90 \%$ of the rolling load applied by the bigger roller achieves comparable results when using the smaller roller. Forces higher than $130 \mathrm{kN}$ even resulted in negative distortion. Given the fact, that conventional inter-pass rolling has to be applied after each layer and still does not achieve comparable reduction in residual distortion, it can be said that side rolling met the expectations and is a much more effective tool than vertical rolling in respect to the distortion. The reason is the successfully restrained lateral deformation by actively applying the load on both sides of the wall.

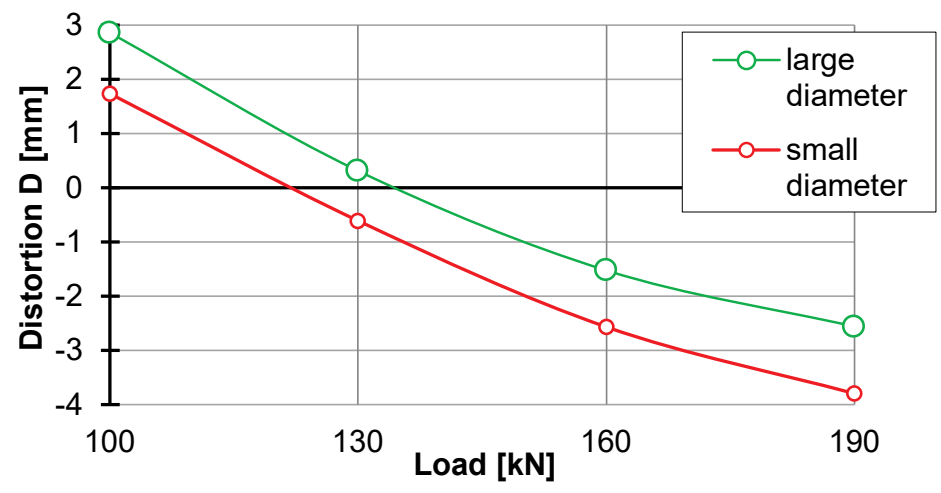

Figure 4: Out-of-Plane Distortion after rolling with a small and a big roller with different loads

Residual Stress. Fig. 5 a) shows all longitudinal residual stress profiles vs. the distance above the substrate. While still clamped, the residual stress of the unrolled control sample along the centre line is fairly constant at around $550 \mathrm{MPa}$, which is significantly lower than the yield value of Ti-6Al-4V deposit (810-870 MPa). This constant tensile stress has only been modelled before in mild steel [7], but never measured. After unclamping, the profile shows a constant drop of residual stress with increasing distance to the substrate, with being compressive in the top layers. This trend is also supported by this model and also reported elsewhere [3], [4], [8]. Side Rolling took place from $3 \mathrm{~mm}$ above the substrate to the top of the wall. In this region, tensile residual stresses were reduced significantly, due to imposed plastic deformation. The stress profile dropped from being $550 \mathrm{MPa}$ and varies between -200 to $+200 \mathrm{MPa}$. This ultimately was the reason for the successful reduction of distortion. Prior to rolling, the contact surface of the wall was uneven, varying by $\pm 0.05 \mathrm{~mm}$ over a nominal width. Therefore, the roller imposed non-uniform strain across the wall, particularly near the surface; where the wall was wider, significantly higher compressive stress can be observed. 
Fig. $5 \mathrm{~b}$ ) shows the contour map of the distorted control and a side-rolled sample. The wall in the control agrees well with the ND profile, with stress varying nearly linearly from tensile to a compressive state towards the top of the wall. The compressive upper and tensile lower region in the substrate shows the same trend. The stress field outside of the HAZ in the substrate is a result of the out-of-plane distortion of the section. Also, rolled plot agrees well with the ND result in this area. The residual stresses within the area of both the wall and the substrate are more uniform. Unlike ND, the resolution of the $\mathrm{CM}$ is high enough to show that side rolling did not induce unintentional gradients in the transverse direction, as it is very uniform along the y-axis.

However, employing a contour analysis with very little smoothing is also sensitive to artefacts induced by the EDM-cut. This type of artefact is very likely the cause of the high gradient in both plots that appears at the interface between the wall and the substrate. The source is attributed to a change in cutting length, as the cutting power density per unit length decreases, causing the cut to proceed slowly through this part of the cross-section. It is surmised that this is also complicated by plasticity effects, when the EDM wire cuts through a region with high tensile stress. Sacrificial material could obviate these artefacts during the cut or a second stress-free control cut near the first contour can be performed to identify the cutting-length-caused power-density artefacts afterwards. As a result, the current $\mathrm{CM}$ analysis has an unknown uncertainty near the interface of wall and substrate in the HAZ. In the same region, the ND did not show sufficient peak intensity in the spectrum for diffraction peak fitting due to texture and path length issues. However, the ND results in the region affected by processing are without concern and compare well with those obtained by CM.
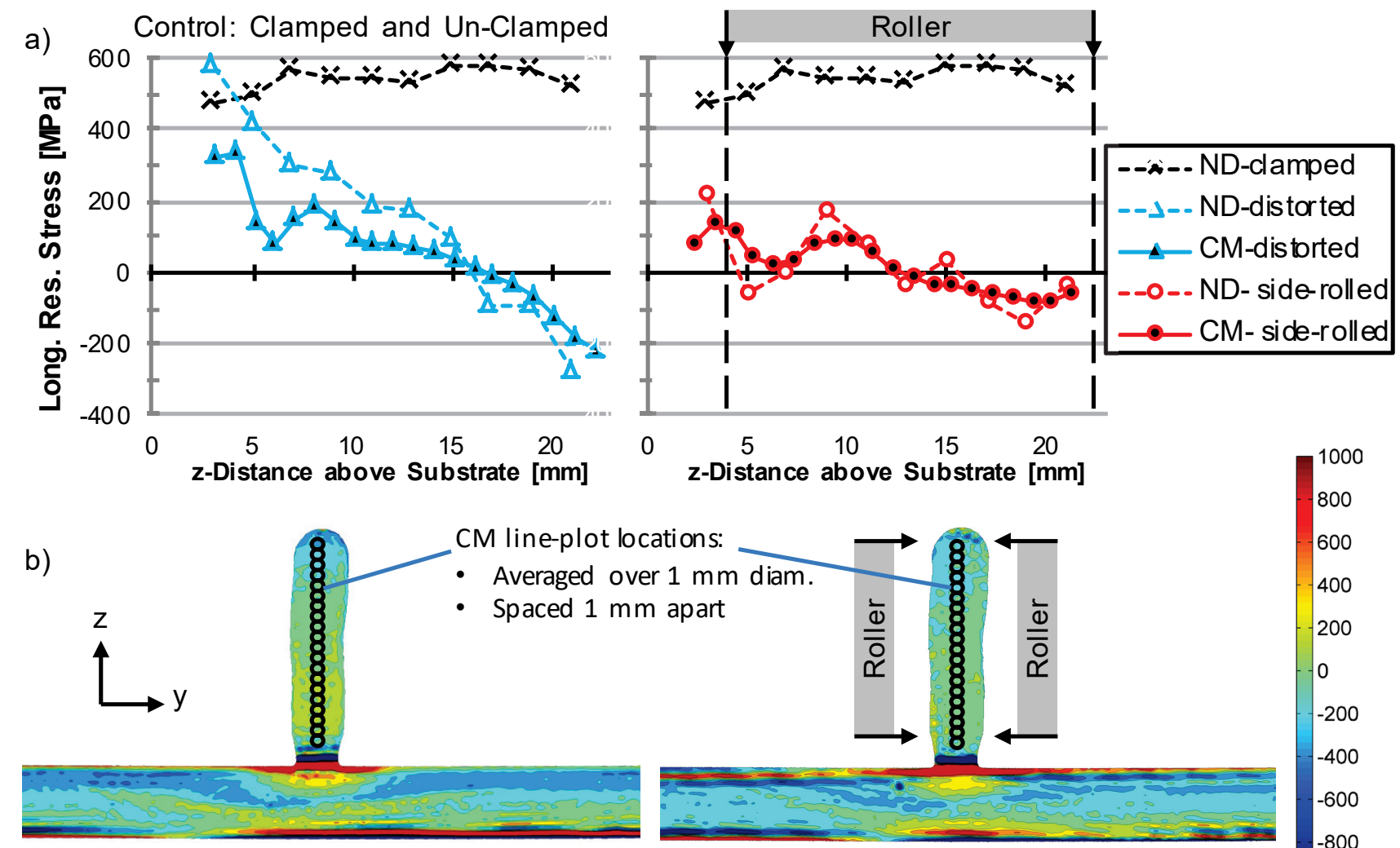

Un-clamped and Distorted (Control)

cations:

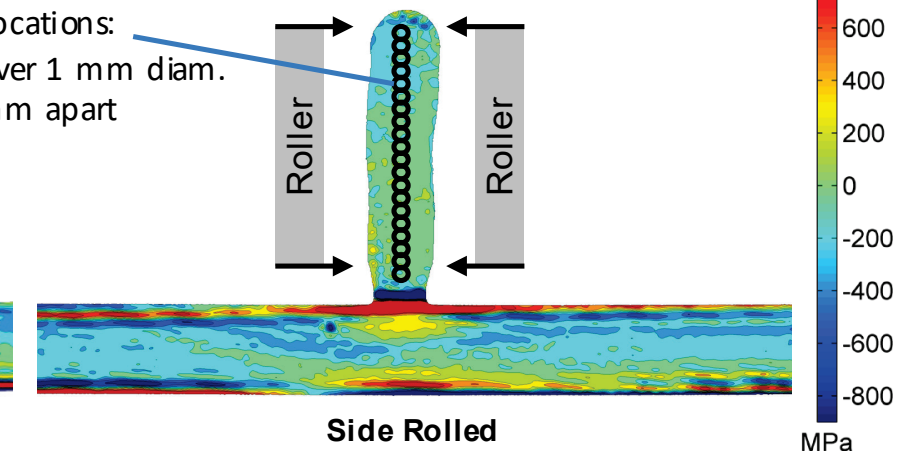

Figure 5: a) Residual stress profiles measured by neutron diffraction (ND - dashed) and contour method (CM - solid): clamped control (black); unclamped and distorted control (blue) and side-rolled (red); b) contour maps of unclamped control and a side-rolled sample

\section{Conclusion}

In this study we have shown that: 
1. Side Rolling has the potential to eliminate longitudinal residual stresses and distortion in straight AM parts entirely. The effect on both is remarkably higher than vertical rolling, which also is being applied after each layer.

2. A smaller roller diameter has a greater effect on both using a constant force. The effect can also be estimated analytically.

3. The compressive strain induced by a flat roller from the side on a WAAM wall is very sensitive the unevenness of the rolled surfaces' profile. A wall profile variation of only $\pm 0.05 \mathrm{~mm}$ can cause residual stress variations around approximately $\pm 200 \mathrm{MPa}$.

4. Before unclamping (which is the condition where cold work is identified to be applied), the longitudinal tensile residual stress has been proven to be constant in each layer. The peak stress is significantly lower than the material's yield value in a single path Ti-6Al-4V WAAM wall.

5. The contour method analysis of the T-shaped single WAAM wall is likely to be sensitive to EDM-cut artefacts caused by steep cutting length changes and plasticity effects. Both must be investigated further.

\section{Acknowledgement}

The authors wish to acknowledge the help and practical support from Joe Kelleher and Clement Bühr at the ENGIN-X Rutherford Appleton Laboratory during the neutron diffraction measurement.

\section{References}

[1] S. W. Williams, F. Martina, a. C. Addison, J. Ding, G. Pardal, and P. Colegrove, "Wire+Arc Additive Manufacturing," Mater. Sci. Technol., vol. 00, no. 0, p. 1743284715Y.000, 2015.

[2] J. Ding, P. Colegrove, J. Mehnen, S. Williams, F. Wang, and P. S. Almeida, “A computationally efficient finite element model of wire and arc additive manufacture," Int. J. Adv. Manuf. Technol., vol. 70, pp. 227-236, 2014. http://dx.doi.org/10.1007/s00170-0135261-x

[3] P. a. Colegrove, H. E. Coules, J. Fairman, F. Martina, T. Kashoob, H. Mamash, and L. D. Cozzolino, "Microstructure and residual stress improvement in wire and arc additively manufactured parts through high-pressure rolling," J. Mater. Process. Technol., vol. 213, pp. 1782-1791, 2013. http://dx.doi.org/10.1016/j.jmatprotec.2013.04.012

[4] F. Martina, M. J. Roy, B. A. Szost, S. Terzi, P. A. Colegrove, S. W. Williams, P. J. Withers, J. Meyer, and M. Hofmann, "Residual stress of as-deposited and rolled wire+arc additive manufacturing Ti-6Al-4V components," Mater. Sci. Technol., vol. 0836, no. April, 2016. http://dx.doi.org/10.1080/02670836.2016.1142704

[5] H. E. Coules, "Contemporary approaches to reducing weld-induced residual stress," Mater. Sci. Technol., vol. 29, no. 1, 2012.

[6] P. Colegrove, J. Ding, M. Benke, and H. Coules, "Application of High-Pressure Rolling to a Friction Stir Welded Aerospace Panel," in Mathematical Modelling of Weld Phenomena 10, C. Sommitsch and N. Enzinger, Eds. Graz, 2013, pp. $691-702$.

[7] J. Ding, P. Colegrove, J. Mehnen, S. Ganguly, P. M. S. Almeida, F. Wang, and S. Williams, "Thermo-mechanical analysis of Wire and Arc Additive Layer Manufacturing process on large multi-layer parts," Comput. Mater. Sci., vol. 50, no. 12, pp. 3315-3322, 2011. http://dx.doi.org/10.1016/j.commatsci.2011.06.023

[8] B. A. Szost, S. Terzi, F. Martina, D. Boisselier, A. Prytuliak, T. Pirling, M. Hofmann, and D. J. Jarvis, "A comparative study of additive manufacturing techniques: Residual stress and microstructural analysis of CLAD and WAAM printed Ti-6Al-4V components," Mater. Des., vol. 89, pp. 559-567, 2016. http://dx.doi.org/10.1016/j.matdes.2015.09.115 